\title{
Parametric Optimization and Performance Analysis of Outer Rotor Permanent Magnet Flux Switching Machine for Downhole Application
}

\author{
Rajesh Kumar*, Erwan Sulaiman, Mahyuzie Jenal, and Fatiah Shafiqah Bahrim \\ Research Center for Applied Electromagnetics, University of Tun Hussein Onn Malaysia, Locked Bag 101, \\ Parit Raja, Batu Pahat, Johor, Malaysia
}

(Received 25 January 2017, Received in final form 21 February 2017, Accepted 23 February 2017)

\begin{abstract}
To empower safe, economical and eco-friendly sustainable solution for enhancing oil and gas productivity from deep water reservoirs, new downhole technologies are recommended. Since electric machine plays leading role in the downhole application, it is a squeezing requirement for researchers to design and develop advanced electric machine. The Recent improvement in technology and uses of high-temperature magnets, permanent magnet flux switching machine (PMFSM) has become one of the appropriate contenders for offshore drilling but fewer designed for downhole due to ambient temperature. Therefore this comprehensive study deals with the design optimization and performance analysis of outer rotor PMFSM for the downhole application. Preliminary, the basic design parameters needed for machine design are calculated mathematically. Then the design refinement technique is implemented through deterministic method. Finally, initial and optimized performance of the machine is compared and as a result the output torque is increase from $16.39 \mathrm{Nm}$ to $33.57 \mathrm{Nm}$ while diminishing the cogging torque and $P M$ weight up to $1.77 \mathrm{Nm}$ and $0.79 \mathrm{~kg}$, respectively. Therefore, it is concluded that purposed optimized design is suitable for the downhole application.
\end{abstract}

Keywords : downhole application, flux switching, optimization, outer rotor, permanent magnet

\section{Introduction}

Energy is the main thrust of the worldwide economy. Fig. 1 demonstrates the anticipated energy prerequisite from various resources to guarantee the improvement of the global economy from now to 2035 [1]. The majority of the increased production of oil and gas in coming decades is from the following two sources.

(i) Mature Fields

(ii) Deep Water Reservoirs

These mature fields today represent more than $70 \%$ of the overall oil and gas production. The generation is gradually declining and the fields will be closed down rashly if the advance technology for enhancing recuperation financially savvy operation and support are not set up [2]. The worldwide oil and gas chase for new oil and gas assets is driving us into ever more profound waters and harsher environment. The most effective method to endeavor more oil and gas resources in the deepwater and

CThe Korean Magnetics Society. All rights reserved.

*Corresponding author: Tel: +60197660121

Fax:+6074536060, e-mail: rajeshkumar@iiiee.edu.pk

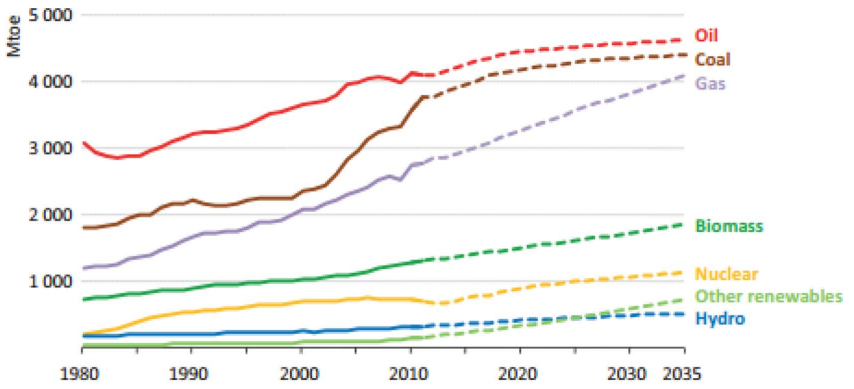

Fig. 1. (Color online) Global energy consumption [1].

develop them in a protected, proficient and all the more ecological way is a challenge. The cost of customarily settled or drifting platforms for processing, which are today generally utilized increases significantly in light of the fact that the stages are exceptionally costly to install and fabricate and for the fixed platforms demounting also costs hundreds of millions dollars afterward. With the traditional technologies, numerous deepwater fields are uneconomical to develop.

Downhole processing, by moving the processing from topside or inland to downhole can not just take out the top stages or somewhat diminish the top territory, but also 
generally improve production, extreme recuperation and preparing productivity while diminishing ecological effects [4].

An electric machine is the core of downhole application because more than $30 \%$ of electrical system failure occurs in the machine shown in Table 1 [5]. The machine must bear the qualities of high reliability, better efficiency, high torque density and easy control. The present standard electrical downhole machine is induction machine which is moderately inefficient. Furthermore, the characteristic shortcoming of low starting torque and high starting current limits induction machine to low-torque, high-speed applications. In applications where high torque is needed, a mechanical gear is regularly added to coordinate the torque, this not just further diminishing the framework efficiency, likewise, debases the framework unwavering quality [6]. On the other hand, permanent magnet (PM) machines having higher efficiencies, higher torque densities and littler volumes, are generally utilized in modern applications to supplant traditional machines, however few have been produced for the downhole applications because of the high atmospheric temperatures in profound wells and the low-temperature stability of PM materials over the time. Today, with the improvement of cutting edge innovations and utilizations of high-temperature magnets, it is progressively fascinating for oil and gas businesses to create PM machines for the downhole applications [7]. A permanent magnet direct current (PMDC) downhole machine has been proposed for the downhole application. The direct current is effortlessly transmitted through PMDC to downhole by decreasing the transmission losses. It is easy to control because it does not require variable frequency drive (VFD). Notwithstanding, it has a couple of downsides, for example, the commutator system in PMDC not only introduces the complexity in assembling, additional losses over the brushes and also causes frequent failure. Furthermore, regular replacement is required every 2-3

Table 1. Component failure in ESP system for the downhole application [5].

\begin{tabular}{cc}
\hline \hline Components & Failure Percentage \\
\hline Assembly & 1 \\
Cable & 21 \\
Sensor & 1 \\
Pump & 30 \\
Gas Handler & 1 \\
Motor & 32 \\
Intake & 4 \\
Protector & 10 \\
Other & 1 \\
\hline
\end{tabular}

years [8]. In order to overcome the problem of brushes, a brushless interior permanent magnet machine (IPM) was developed but it requires additional cooling facility [9].

The permanent magnet flux switching machine (PMFSM) has a brief history and is a moderately new sort of PM machines. The primary PMFSM was accounted for as a solitary phase alternator in 1955 using a low execution magnet depicted in Fig. 2(a), while a three-phase machine was presented in 1997 where ferrite was embraced to observe the flux centering impact appeared in Fig. 2(b) $[10,11]$. More recently, there have been revived research interests in PMFSM, most likely because of number of saw advantages. Since all active parts such as armature windings and PM placed on the stator, straightforward yet viable machine cooling can be effortlessly connected [12]. Besides, extra preferences such as robust rotor structure, high torque and flux densities, high efficiency and better flux weakening capability are exhaustively analyzed and checked for numerous applications [13-15].

Setting the rotor on the external surface will produce more torque, contrasted with the routine internal rotor [16]. However, investigation on the PMFSM has, for the most part, centered on the electromagnetic examination and optimization of the inward rotor type machines with scarcely gave careful consideration to the external rotor PMFSM [17-19].

This paper primarily focused on design and optimization outer rotor PMFSM for the downhole application. Firstly, design key parameters are derived by utilizing mathematical formulas then it is modeled and simulated on 2DFEA Finite Element Analysis (FEA) package, JMAGDesigner ver.14.0. The purposed design is unable to produce torque of $25 \mathrm{Nm}$. Therefore, the machine is optimized through the deterministic approach where design free parameters are adjusted in order to enhance the output of the machine. Finally, the performance comparison of initial and improved design is carried out in the last section.

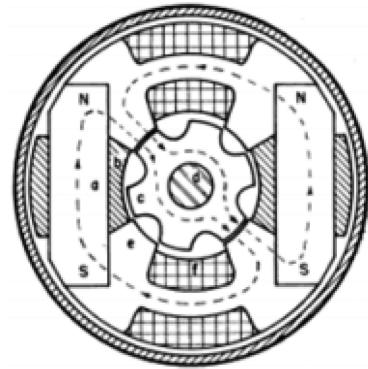

(a)

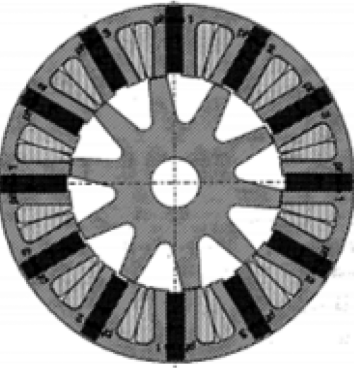

(b)
Fig. 2. (a) Single phase alternator (b) Three phase brushless machine. 


\section{Geometric Topology}

The basic design parameters are constrained by geometric relationship, interpreted in a magnified local structure shown in Fig. 3(a). The stator slot ought to be even multiple of phase numbers. In this manner, the relationship between stator slot number and $N_{s}$ rotor pole number $N_{r}$ is [20]

$$
N_{r}=\frac{(12 \pm n) \times N_{s}}{6}
$$

where $n$ is a positive whole number which ought not to be multiple of three. In order to achieve zero resultant magnetic force, $N_{r}$ is chosen to be an even number. The key outline parameters such as stator tooth arc width $\beta_{s}$, rotor pole arc width $\beta_{r}$, permanent magnet arc width $\beta \mathrm{pm}$ and stator armature slot width arc $\beta_{\text {slot }}$ preliminary fixed as

$$
\beta_{r}=\beta_{s}=\beta_{p m}=\frac{\beta_{s l o t}}{3}=\frac{\pi}{3 N_{s}}
$$

Simultaneously, the additional relationship between stator inner radius $R_{s i}$, and outer radius $R_{s o}$, stator back length $h_{y s}$ and rotor yoke length $h_{y r}$ are originally settled at

$$
\begin{aligned}
& R_{s i}=\frac{R_{s o}}{2} \\
& h_{y r}=1.5 \times h_{y s}
\end{aligned}
$$

Therefore, ratio between stator inner radius and stator outer radius is 0.5 . Moreover, to get adequate rotor saliency, the rotor pole height $h_{p r}$ is set as

$$
h_{p r}=\frac{R_{s o}}{8}
$$

In addition, stator slot winding area $A_{\text {slot }}$ can be resolved as

$$
A_{\text {slot }}=\frac{R_{s o}^{2} \times \sin \left(\frac{\pi}{2 N_{s}}\right)^{2}}{2 \tan \left(\frac{\pi}{N_{s}}\right)}
$$

Furthermore, number of turns $N_{a}$ for one stator slot and peak injected current $I_{m}$ in each coil can be determined as

$$
\begin{aligned}
& N_{a}=\frac{2 A_{\text {slot }} \times \alpha}{\pi d^{2}} \\
& I_{m}=\frac{J a \times A_{\text {slot }} \times \alpha}{2 N_{a}}
\end{aligned}
$$

where, $\alpha$ is filling component, $d$ is the diameter of wire and $J a$ is the peak injected current density. At last, the rotor outer radius can be derived as

$$
R_{r o}=\left(\frac{9}{8}+\frac{\pi}{2 N_{s}}\right) \times R_{s o}+g
$$

Table 2. Specifications of initial outer rotor PMSFM for the downhole application.

\begin{tabular}{cccc}
\hline \hline Parameters & Abbreviation & Value & Units \\
\hline Stator slot number & $N_{s}$ & 12 & \\
Rotor pole number & $N_{r}$ & 22 & \\
Rotor outer radius & $R_{r o}$ & 50 & $\mathrm{~mm}$ \\
Rotor inner radius & $R_{r i}$ & 40.5 & $\mathrm{~mm}$ \\
Stator inner radius & $R_{s i}$ & 20 & $\mathrm{~mm}$ \\
Stator outer radius & $R_{s o}$ & 40 & $\mathrm{~mm}$ \\
Stator back length & $h_{y s}$ & 3 & $\mathrm{~mm}$ \\
Rotor yoke length & $h_{y r}$ & 4.5 & $\mathrm{~mm}$ \\
Rotor pole arc width & $\beta_{r}$ & 5 & $\circ$ \\
Stator tooth arc width & $\beta_{s}$ & 5 & $\circ$ \\
Permanent magnet arc width & $\beta_{p m}$ & 5 & $\circ$ \\
Slot area & $A_{s l o t}$ & 50.732 & $\mathrm{~mm}$ \\
Air gap & $g$ & 0.5 & $\mathrm{~mm}$ \\
Stack length & $l$ & 200 & $\mathrm{~mm}$ \\
Number of Turns & $N_{a}$ & 33 & \\
Synchronous speed & $\omega$ & 1000 & $\mathrm{rpm}$ \\
Armature current density & $J a$ & 30 & $\mathrm{~A} / \mathrm{mm}^{2}$ \\
Split ratio & $\lambda$ & 0.8 & \\
Permanent Magnet Weight & $W_{p m}$ & 1.26 & $\mathrm{~kg}$ \\
\hline
\end{tabular}

where, $g$ is the air gap. The complete schematic of proposed design is depicted in Fig. 3(b) is developed by key geometric parameters of outer rotor PMFSM shown in Table 2, that are ascertained through above mentioned equations.

\section{Optimization}

Preliminary, the performance of proposed machine design is computed through 2D-FEA, yet the objective torque is not accomplished for the downhole application. To handle this issue, design free parameters, L1 to L7 defined in rotor and stator sides as illustrated in Fig. 4, optimized through deterministic technique. The deterministic method is utilized to locate the greatest execution of machine by changing the design free parameters while keeping the air gap constant. The flow chart of the deterministic method is depicted in Fig. 5. Basically, the design parameters are classified into groups such as those identified with rotor core, PM shape and armature coil slot shape. The rotor parameters are rotor radius (L1), rotor pole width (L2), and rotor pole height (L3). The PM shape parameters are PM width (L4), PM radial length (L5) while armature coil slot consist of armature coil width (L6), and armature coil height (L7), respectively. 


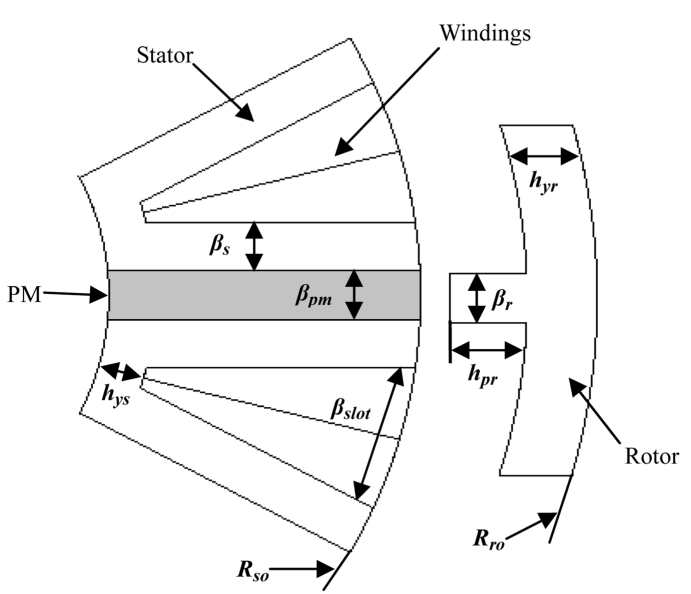

(a)

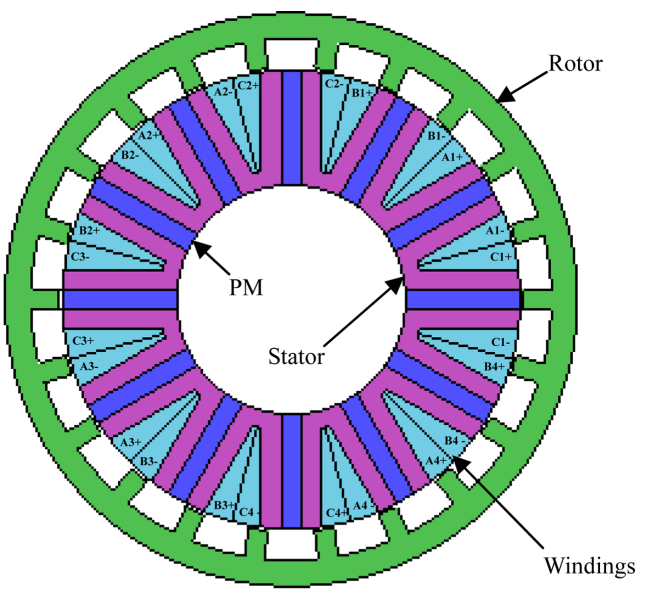

(b)

Fig. 3. (Color online) (a) Magnified local structrue (b) Complete schematic of outer rotor PMFSM.

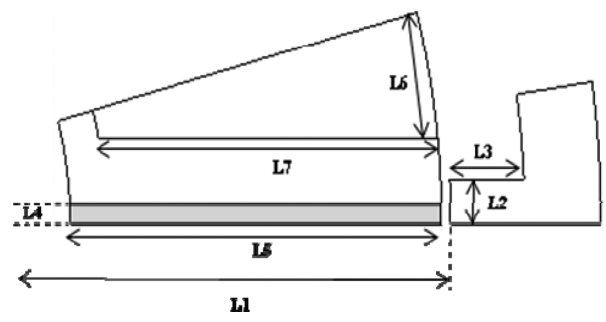

Fig. 4. Design free parameters of 12s-22p PMFSM.

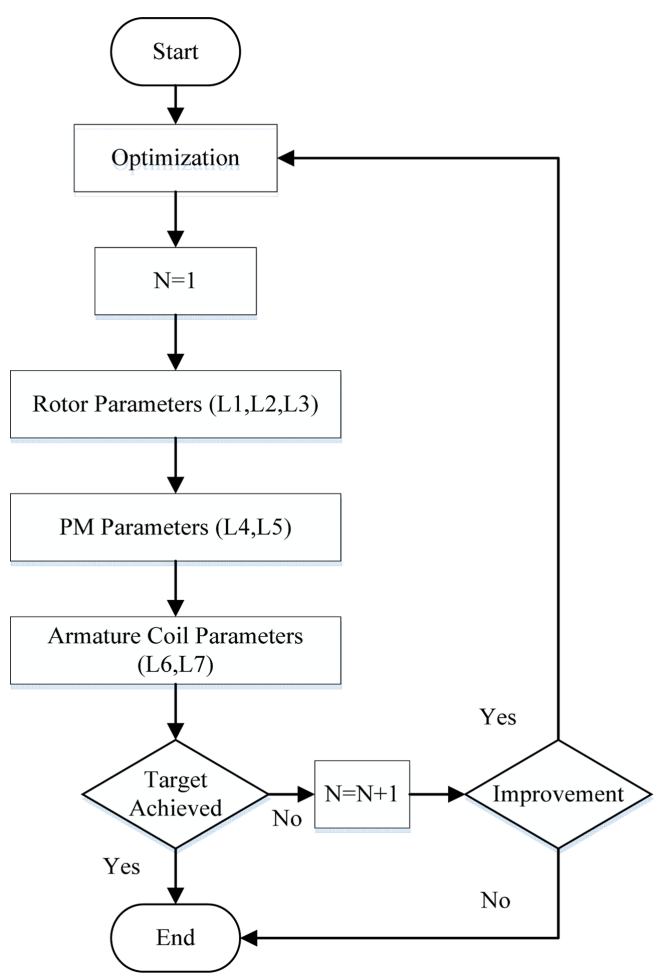

Fig. 5. (Color online) Work flow diagram of deterministic approach.

\subsection{Split Ratio}

In outer rotor machines, the ratio of stator external radius to rotor external radius is necessary to be improved since it fundamentally impacts torque output yield line. At initial stage, it has been fixed at 0.8 , which implies the stator will possess $80 \%$ of machine size which is valid according to outer rotor PMFSM design principle [21]. The ideal estimation of split ratio is gotten by shifting L1 while keeping all parameters consistent. This strategy rehashed for several cycles so the final value can be achieved. The maximum value of torque is accomplished when the ratio is set at 0.86 as shown in Fig. 6. In external rotor PMFSM, the larger split ratio offer completely use of stator internal space which produces higher slot area and consequently higher average torque.

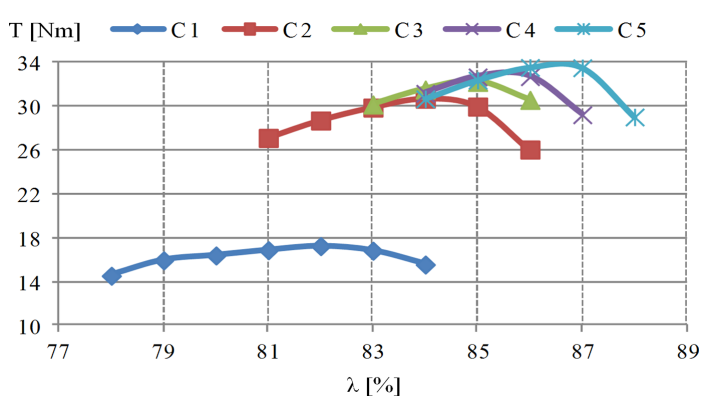

Fig. 6. (Color online) Split ratio analysis of outer rotor PMFSM.

\subsection{Rotor Pole Width \& Height}

For concentrating the stream of flux while decreasing the vibration and windage losses in proposed design, the rotor pole width L2 and height L3 need to be refined. Initially, they are set at $3.49 \mathrm{~mm}$ and $5 \mathrm{~mm}$ respectively, 


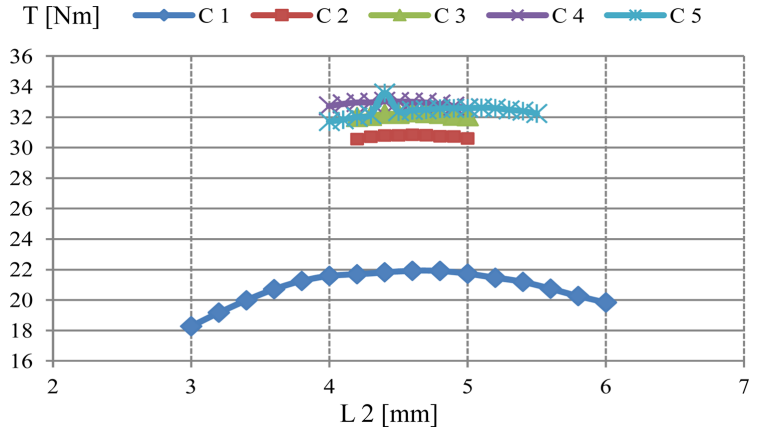

Fig. 7. (Color online) Rotor pole width versus torque investigation.

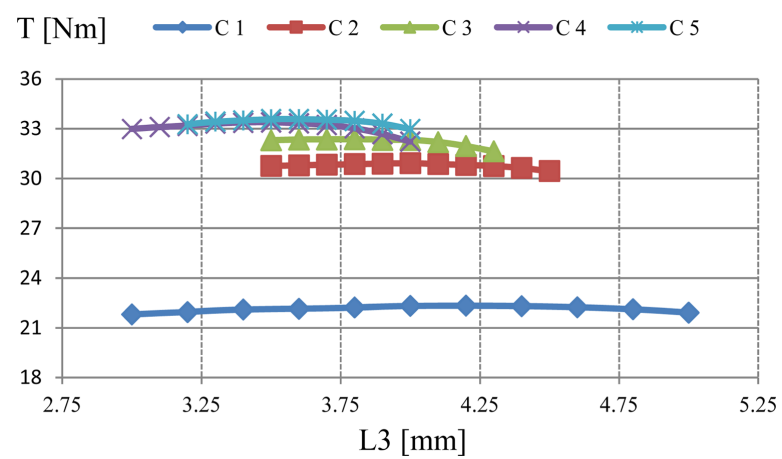

Fig. 8. (Color online) Rotor pole height variation at different cycles.

where the output torque was $16.39 \mathrm{Nm}$ beneath from focused range. Hence, these two parameters should be refined with a specific end goal to improve the performance of the machine. The first step is to adjust L1 by keeping all other parameters constant. Then, L2 is modified in order to obtain the maximum value of output torque. This procedure is repeated for multiple cycles so that the best value can be achieved. By picturing Fig. 7 and 8 , it can be viewed that the pinnacle yield torque is achieved after five cycles where rotor pole width and height are settled at $4.4 \mathrm{~mm}$ and $3.6 \mathrm{~mm}$ correspondingly.

\subsection{Permanent Magnet Width and Radial Length}

In numerous applications, high utilization of PM causes the undesirable impacts of high cogging torque that can aggravate performance of the machine. Hence it is compulsory to characterize the finest estimation of PM in machine designing. This could be possible by modifying PM width L4 while keeping other parameters constant, through deterministic approach as exhibited in Fig. 9. In basic design, the PM weight was figured around $1.26 \mathrm{~kg}$. After implementation of the optimization process for several cycles, the PM length changed from $3.49 \mathrm{~mm}$ to $1.9 \mathrm{~mm}$ that decreases the weight to $0.79 \mathrm{~kg}$. The next step is to adjust PM radial length L5 because it influences

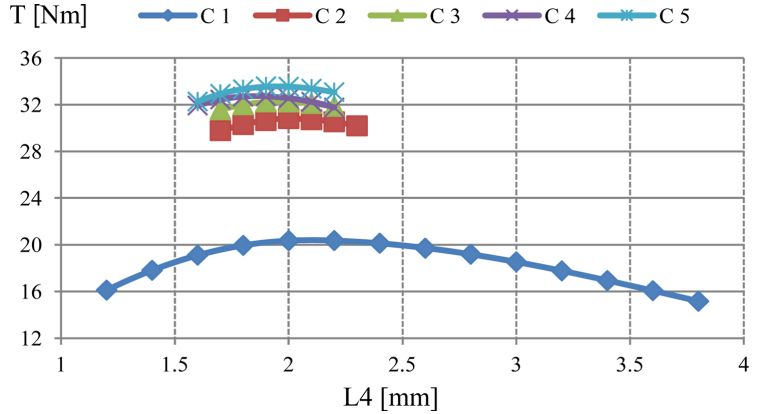

Fig. 9. (Color online) Deviation in PM width with respect to torque.

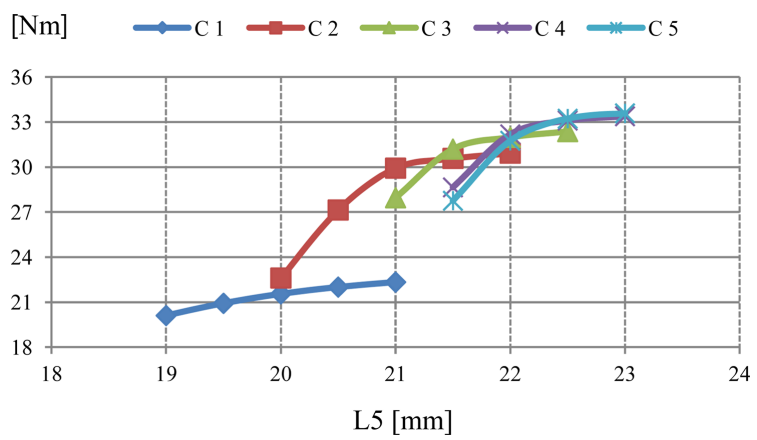

Fig. 10. (Color online) PM radial length against torque analysis.

the torque characteristics, loss, and efficiency. The radial length preliminary fixed at $19 \mathrm{~mm}$, which changes to 23 $\mathrm{mm}$ after refinement shown in Fig. 10. The optimization of both parameters has built the electromagnetic torque.

\subsection{Number of Turns}

The numbers of turns play fundamental part in the enhancement of electric machine performance. Subsequently, the necessary armature slot area $A_{\text {slot }}$ is dictated by shifting armature coil height, L6 and armature coil width, L7 to oblige whole number of turns, Na for armature loop. In the deterministic method, armature slot area parameters L6 and L7 are dealt with while keeping different parameters examined above constant. The plot of torque

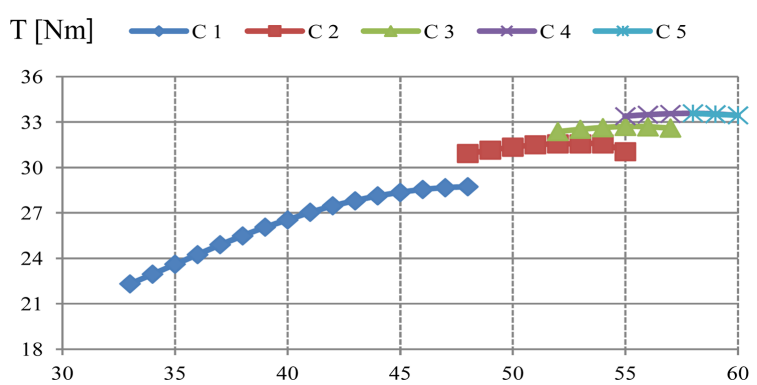

Fig. 11. (Color online) Average output torque at various number of turns. 
versus $\mathrm{Na}$ is portrayed in Fig. 11. The maximum torque is acquired when $\mathrm{Na}$ is 58 turns, L6 is $13.94 \mathrm{~mm}$ and L7 is $21.20 \mathrm{~mm}$, respectively. The increment in electromagnetic torque is mainly due more magnetic flux induced by the higher number of turns. Although, armature current density remains same but slot area has been enlarged.

\section{Results \& Performance Comparison}

The performance correlation is completed under open circuit and close circuit. The no load examination incorporates flux linkage and distribution, cogging torque and induced voltages while load investigation consist of torque characteristic, torque-power versus speed curve, and efficiency analysis.

\subsection{Flux Linkage}

For initial and optimized design, the total flux in the machine is generated by PM only when the rotor is rotated at speed of $1000 \mathrm{rpm}$ while the armature current density is fixed at $0 \mathrm{~A} / \mathrm{mm}^{2}$. From Fig. 12, in enhanced design, the u-phase flux linkage of $12 \mathrm{~s}-22 \mathrm{p}$ has been

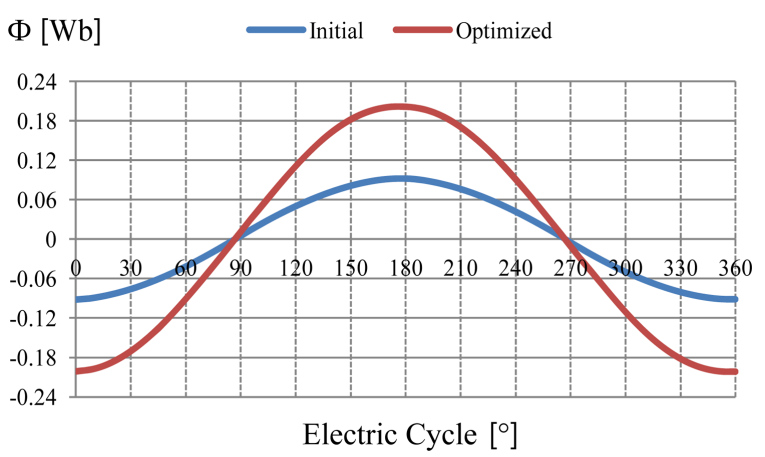

Fig. 12. (Color online) U-phase flux linkage of initial and enhanced design.

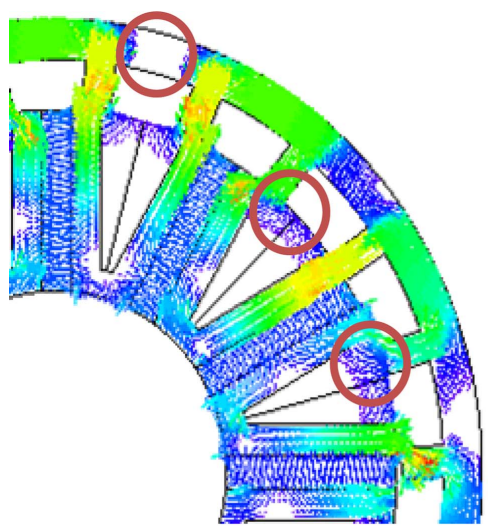

(a)

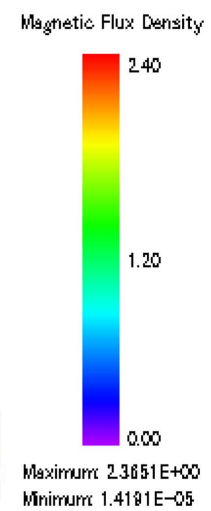

Mrimum 141 名1 -05
Fig. 13. (Color online) Flux distribution of $12 \mathrm{~s}-22 \mathrm{p}$ (a) Initial (b) Optimized. increased to $0.2 \mathrm{~Wb}$ which is twice of preliminary design. The flux is doubled because the rotor pole height is shortened so it means the flux will take shorter time to complete one cycle.

\subsection{Flux Distribution}

The objective of flux distribution is to control the stream of flux while checking the impact of flux saturation in the machine. Meanwhile, Fig. 13(a) shows that initial design experiences flux cancellation effect and leakage highlighted in red circles. After implementation of deterministic optimization technique, the leakage factor is improved from 0.75 to 0.95 while wiping out the effect of flux cancellation depicted in Fig. 13(b).

\subsection{Cogging Torque}

It is additionally called as detent or no-current torque that makes noise and vibration in machine operation. The PM produced cogging torque investigation for one electrical cycle is illustrated in Fig. 14. The cogging torque waveform has 6 numbers of cycles that are determined as [22]

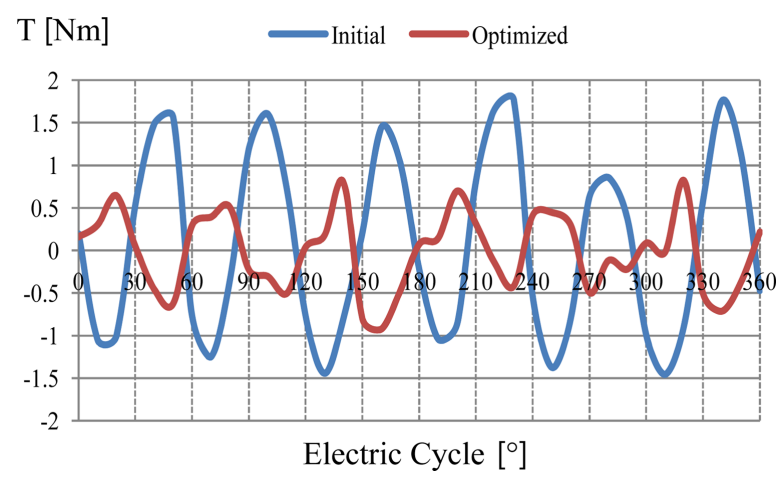

Fig. 14. (Color online) Cogging torque analysis for one electric cycle.

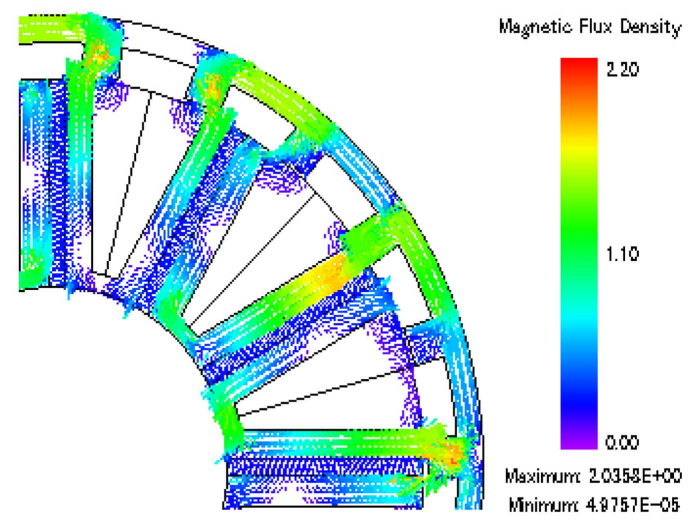

(b)
Maximum $20359+\infty$

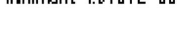




$$
\begin{aligned}
& N_{p}=\frac{N_{r}}{H C F\left[N_{r} N_{s}\right]} \\
& N_{e}=\frac{N_{p} N_{s}}{N_{r}}
\end{aligned}
$$

The preparatory design of outer rotor PMFSM for the downhole application with 12slot-22poles has high crest to crest cogging torque of around $3.2 \mathrm{Nm}$ which is which is reduced to is about $1.74 \mathrm{Nm}$ after optimization due to decrement in PM weight.

\subsection{Induced Voltages}

Further examination of the both designs on back-Emf in no load condition is carried out at the speed of $1000 \mathrm{rev} /$ $\mathrm{m}$. The outcomes acquired for back-Emf are plotted in Fig. 15. The improved design has higher induced voltages than the initial design in light of the fact that the induced emf $(E)$ is directly proportional to the flux linkage $(\phi)$, illustrated in Eq. (12) while $k$ is the constant value, depends on the machine geometry and $\omega$ is speed.

$$
E=k \phi \omega
$$

As flux is doubled after optimization, the induced voltages of optimized design are much higher than the

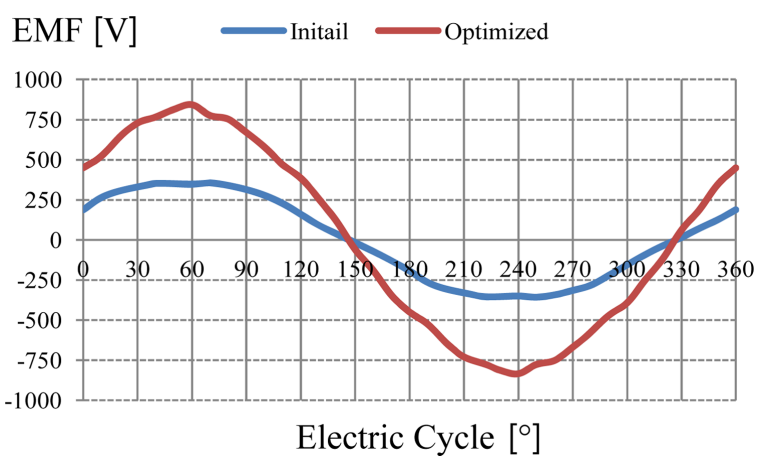

Fig. 15. (Color online) Induced voltage comparison of initial and optimized design.

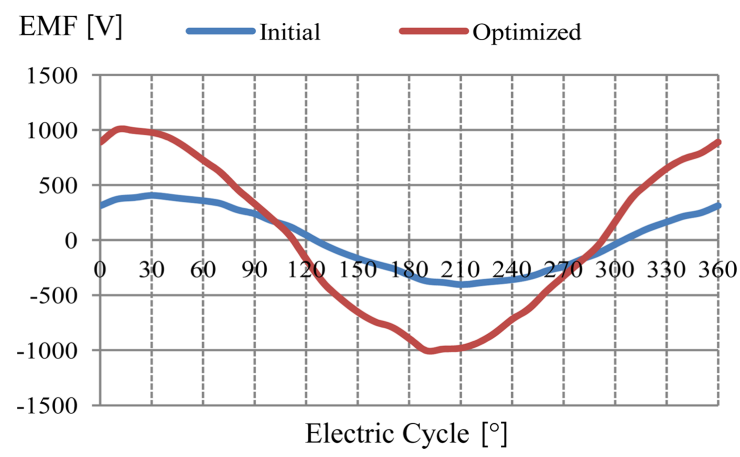

Fig. 16. (Color online) Induced voltage of initial and enhanced design under load condition. initial design under load condition as shown in Fig. 16. Furthermore, induced voltages of optimized design under base and maximum speed is illustrated in Fig. 17, where magnetic flux is almost same but the speed is changed that is why maximum speed has high value of induced voltages.

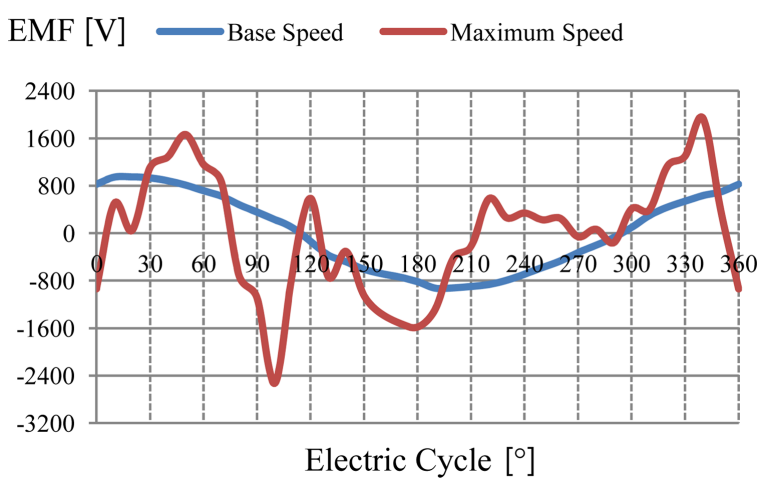

Fig. 17. (Color online) Back-emf of optimized design under base and maximum speed.

In addition, induced voltages of optimized design are greater than applied voltages but can be used for regenerative braking system in order to charge the source.

\subsection{Average Output Torque at Various Armature Cur- rent Densities}

The average electromagnetic torque of proposed configuration can be computed as [23]

$$
T_{\text {avg }}=\frac{\pi}{8} N_{r} K_{d} B_{g} J_{a} A_{\text {slot }} R_{s o} l \alpha
$$

Where $B_{g}$ is maximum air gap flux density at no load condition, $K_{d}$ is leakage factor which is taken as 0.75 for initial design while for improved design it is 0.95 . The obtained results from calculation and simulation are plotted in Fig. 18, in which armature current density is

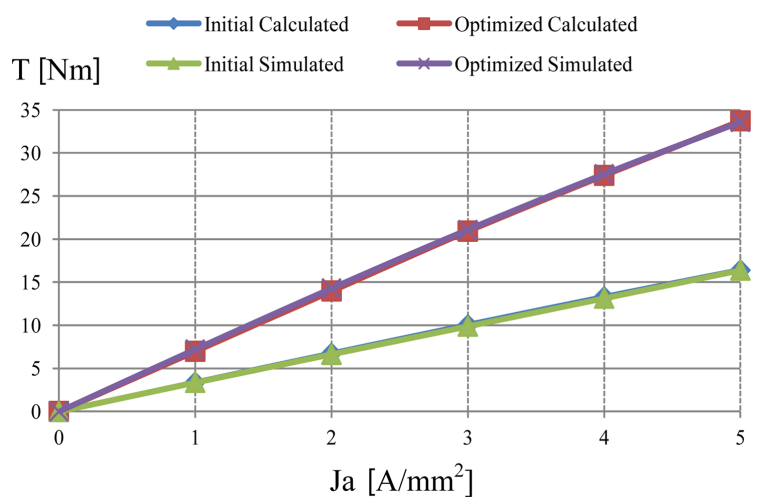

Fig. 18. (Color online) Torque analysis at different armature current densities. 
varied from $0 \mathrm{~A} / \mathrm{mm}^{2}$ to $5 \mathrm{~A} / \mathrm{mm}^{2}$. For initial design, the highest calculated and simulated output torque of 16.39 $\mathrm{Nm}$ and $16.61 \mathrm{Nm}$ were acquired at $5 \mathrm{~A} / \mathrm{mm}^{2}$. After design improvement, the maximum simulated and calculated torque of $33.57 \mathrm{Nm}$ and $33.67 \mathrm{Nm}$ respectively are obtained at $5 \mathrm{~A} / \mathrm{mm}^{2}$ which is approximately $51.17 \%$ greater than initial design.

\subsection{Torque-Power versus Speed Characteristic Curve}

For starting and refined outer rotor PMFSM for the downhole application, the torque and power versus speed curve is plotted in Fig. 19 and 20. At the base speed $2406.55 \mathrm{r} / \mathrm{min}$ and $973.32 \mathrm{r} / \mathrm{min}$, the maximum torque of $16.39 \mathrm{Nm}$ and $33.57 \mathrm{Nm}$ is obtained and torque start to decline if the machine is operated beyond the base speed. The power accomplished by preliminary and improved design is $4.13 \mathrm{~kW}$ and $3.84 \mathrm{~kW}$ respectively. The improved

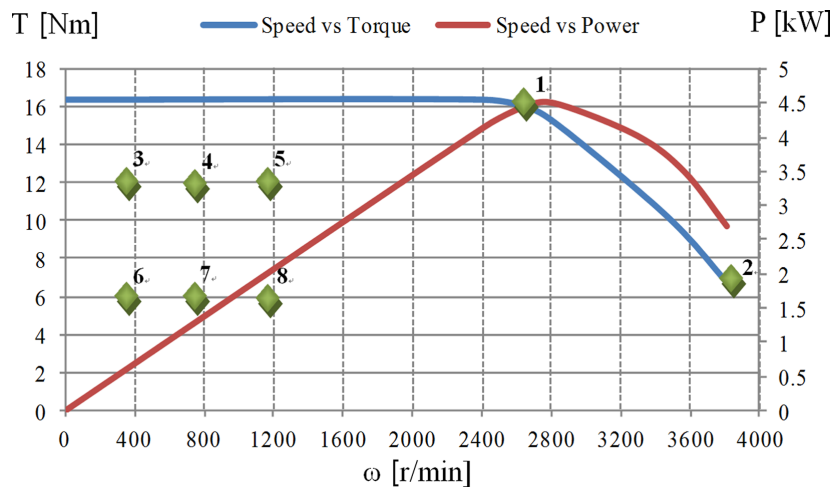

Fig. 19. (Color online) Torque-power versus speed characteristic curve of initial design.

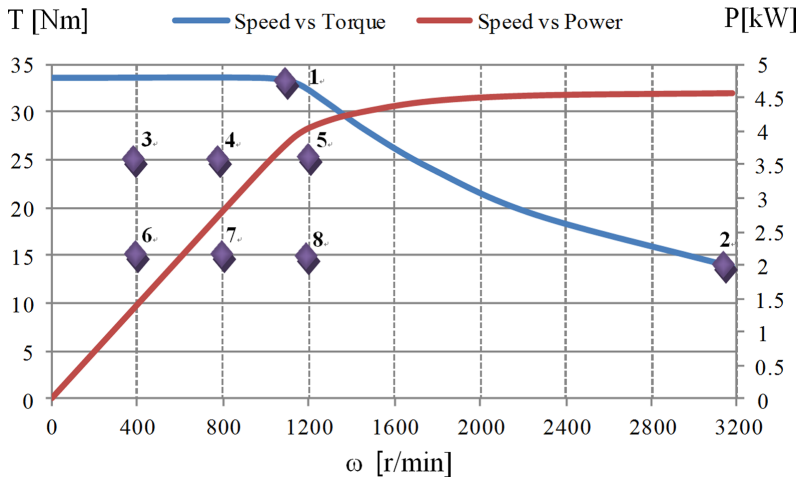

Fig. 20. (Color online) Torque and power against speed analysis for optimized design.

design has less power than initial design but it is still above the targeted value.

\subsection{Machine Losses and Efficiency Predictions}

The motor loss and efficiency are figured by finite element analysis considering copper losses in the armature winding and iron losses in all laminated cores. The particular operating points at maximum torque and regular operating point under light load driving condition noted as No. 1 to No. 8 are already specified in torque-power versus speed graph for initial and optimized design. Meanwhile, the detail losses investigation and motor efficiencies of the initial and improved design are summarized in Table 3 accordingly. In particular, point 1 and 2 represents the maximum operating torque and speed of both designs whereas point 3 up to point 8 falls under the similar average operating region of initial and optimized design.

Table 3. Specifications of initial outer rotor PMSFM for the downhole application.

\begin{tabular}{|c|c|c|c|c|c|c|}
\hline $\begin{array}{l}\text { Machine } \\
\text { Designs }\end{array}$ & $\begin{array}{l}\text { Operat. } \\
\text { Points }\end{array}$ & $\begin{array}{l}\text { Speed } \\
(\mathrm{r} / \mathrm{min})\end{array}$ & $\begin{array}{c}\text { Output Power } \\
(\mathrm{kW})\end{array}$ & $\begin{array}{c}\text { Iron Loss } \\
(\mathrm{kW})\end{array}$ & $\begin{array}{c}\text { Copper Loss } \\
(\mathrm{kW})\end{array}$ & $\begin{array}{l}\text { Eff. } \\
(\%)\end{array}$ \\
\hline \multirow{8}{*}{ Initial } & 1 & 2406.5 & 4.13 & 0.20 & 0.05 & 94.08 \\
\hline & 2 & 3809.3 & 2.69 & 0.29 & 0.05 & 88.45 \\
\hline & 3 & 400 & 0.50 & 0.01 & 0.03 & 91.22 \\
\hline & 4 & 800 & 1.00 & 0.03 & 0.03 & 93.57 \\
\hline & 5 & 1200 & 1.50 & 0.06 & 0.03 & 93.93 \\
\hline & 6 & 400 & 0.25 & 0.01 & 0.009 & 92.15 \\
\hline & 7 & 800 & 0.50 & 0.03 & 0.009 & 92.10 \\
\hline & 8 & 1200 & 0.75 & 0.06 & 0.009 & 91.17 \\
\hline \multirow{8}{*}{ Optimized } & 1 & 973.3 & 3.42 & 0.08 & 0.10 & 95.02 \\
\hline & 2 & 3175.9 & 4.58 & 0.12 & 0.10 & 95.33 \\
\hline & 3 & 400 & 1.04 & 0.01 & 0.06 & 93.09 \\
\hline & 4 & 800 & 2.09 & 0.03 & 0.06 & 95.37 \\
\hline & 5 & 1200 & 3.14 & 0.08 & 0.06 & 95.57 \\
\hline & 6 & 400 & 0.62 & 0.01 & 0.03 & 93.09 \\
\hline & 7 & 800 & 1.25 & 0.02 & 0.03 & 95.07 \\
\hline & 8 & 1200 & 1.88 & 0.04 & 0.03 & 95.41 \\
\hline
\end{tabular}


Table 4. Overall performance comparison of initial and optimized design.

\begin{tabular}{ccc}
\hline \hline Items & Initial & Optimized \\
\hline Torque $(\mathrm{Nm})$ & 16.39 & 33.57 \\
Power $(\mathrm{kW})$ & 4.1 & 4.5 \\
Speed $(\mathrm{r} / \mathrm{min})$ & 3809.3 & 3175.9 \\
Output power $(\mathrm{kW})$ & 11.34 & 18.05 \\
Iron losses $(\mathrm{kW})$ & 0.71 & 0.42 \\
Copper losses $(\mathrm{kW})$ & 0.25 & 0.50 \\
Efficiency $(\%)$ & 92.08 & 94.74 \\
\hline
\end{tabular}

At each design's base speed where highest torque is accomplished, the optimized machine gives off an impression of being the most astounding productivity with $94.74 \%$ in spite of the fact that it has the most copper losses, trailed by initial machine design with $92.08 \%$. Besides this, while running at the normal operating points, the maximum efficiency is acquired for optimized design at point 5 with the consequence of $95.57 \%$. The summarized performances of both machine designs are outlined in Table 4.

\section{Conclusion}

This paper has introduced the design modeling and performance analysis of outer rotor PMFSM for the downhole application. The optimization technique has been clearly described for the accomplishment of focused performance. As an outcome, the proposed machine has better torque, efficiency and low cogging torque when contrasted with the initial design. The optimized machine design has enhanced approximately $51.17 \%$ of maximum torque while lessening the PM weight by $37.3 \%$. The diminishment in PM weight makes machines lighter and simple to manufacture. Finally, it can be concluded with all the analytical study that optimized design of outer rotor PMFSM is one of the prominent candidates for the downhole application.

\section{Acknowledgement}

This research work was promoted by Research, Innovation, Commercialization and Consultancy (ORICC) UTHM, Batu Pahat under Vot number U519 and Ministry of Higher Education Malaysia (MOHE).

\section{References}

[1] World Energy Outlook, International Energy Agency
(2013) pp. 63.

[2] Oil and Gas Industries Technology Master Plan, European Oil and Gas Innovation Forum (2004) pp. 4.

[3] I. Sandrea and R. Sandrea, Oil and Gas Journal (2007) pp. 1-8.

[4] A. Chen, R. B. Ummaneni, R. Nilssen, and A. Nysveen, $13^{\text {th }}$ International Power Electronics and Motion Conference, Poland (2008) pp. 814-818.

[5] N. Griffiths and S. Breit, $35^{\text {th }}$ Workshop on Geothermal Reservoir Engineering, USA (2010).

[6] A. Chen, Ph.D Thesis, Norwegian University of Science and Technology, Norway (2011) pp. 1-141.

[7] A. Chen, R. Nilssen, and A. Nysveen, IEEE Trans. Ind. Appl. 46, 779 (2010).

[8] M. Solesa and V. Sagalovskiy, MEALF, Oman (2007).

[9] Z. Bingyi, L. Bingxue, F. Guihong, and Z. Fuyu, IEEE International Conference on Mechatronics and Automation, China (2007) pp. 1011-1016.

[10] S. E. Rauch and L. J. Johnson, AIEE Trans. Power Appl. Sys. 74, 1261 (1995).

[11] E. Hoang, A. H. B. Ahmed, and J. Lucidame, Switching Flux PM Polyphased Synchronous Machines, $7^{\text {th }}$ European Conference on Power Electronics Applications 3, 903 (1997).

[12] Z. Q. Zhu, Y. Pang, D. Howe, S. Iwasaki, R. Deodhar, and A. Pride, IEEE Trans. Magn. 41, 4277 (2005).

[13] C. S. Walter, H. Polinder, and J. A. Ferreira, IEEE Journal of Emerging and Selected Topics in Power Electronics 1, 327 (2013).

[14] Z. Q. Zhu, J. T. Chen, and D. Howe, IEEE Trans. Magn. 44, 4313 (2008).

[15] M. Jenal, E. Sulaiman, M. Z. Ahmad, F. Khan, and M. F. Omar, XXII International Conference on Electrical Machines, Switzerland (2016) pp. 2399-2405.

[16] C. V. Aravind, M. Norhisam, I. Aris, D. Ahmad, and M. Nirei, IEEE SCORED, Malaysia (2011) pp. 294-299.

[17] W. Xu, J. Zhu, Y. Zhang, Y. Wang, Y. Li, and J. Hu, $20^{\text {th }}$ Australian Universities Power Engineering Conference (2010).

[18] M. Jenal, E. Sulaiman, and R. Kumar, J. Magn. 21, 537 (2016).

[19] M. Jenal, E. Sulaiman, F. Khan, and Md. Z. Ahmad, Applied Mechanics and Materials 785, 274 (2015).

[20] W. Fei, P. C. K. Luk, J. X. Shen, Y. Wang, and M. Jin, IEEE Trans. Ind. Appl. 48, 1496 (2012).

[21] R. Kumar, E. Sulaiman, F. Khan, L. I. Jusoh, and F. S. Bahrim, $2^{\text {nd }}$ International Conference on Science and Technology for Sustainability (2016).

[22] A. Zulu, Ph.D Thesis, Newcastle University, United Kingdom (2010).

[23] J. X. Shen, Y. Wang, C. F. Wang, W. Z. Fei, and P. C. Luk, The International Journal for Computation and Mathematics in Electrical and Electronic Engineering 30, 48 (2011). 